\title{
A CASE ON VENDOR SELECTION METHODOLOGY: AN INTEGRATED APPROACH
}

\author{
NIKHIL CHANDRA SHIL \\ nikhilacc@yahoo.com \\ Senior Lecturer, Department of Business Administration \\ East West University, Dhaka, Bangladesh
}

\begin{abstract}
Vendor selection methodology is a highly researched area in supply chain management literature and a very significant decision taken by supply chain managers due to technological advances in the manufacturing process. Such research has two basic dimensions: one is related to the identification of variables affecting the performance of the vendors and the other deals with the methodology to be applied. Most of the research conducted in this area deal with the upfront selection of vendors. However, it is very common to have a list of dedicated vendors due to the development of sophisticated production technologies like just in time (JIT), a lean or agile manufacturing process where continuous flow of materials is a requirement. This paper addresses the issue of selecting the optimal vendor from the internal database of a company. Factor analysis, analytical hierarchy process and regression analysis is used in an integrated way to supplement the vendor selection process. The methodology presented here is simply a proposal where every possible room for adjustment is available.
\end{abstract}

\section{INTRODUCTION}

The supplier is one of the five competitive forces holding bargaining power as per the Competitive Forces Model defined by Porter of the Harvard Business School in 1979 (Porter, 1980:397). The study on supplier selection started even long before that, during the 1960s. The strategy of suppliers became so unpredictable that a new technology, namely just in time (JIT), developed where the manufacturing plant either owns its suppliers or suppliers are outsourced under a common understanding that they are always ready to supply the materials required by the manufacturing plant in time. Still, JIT remains a dream for most manufacturing units across the world and dependency on suppliers has increased tremendously due to the scarcity, variety and quality of raw materials. Greater dependence on suppliers increases the need for strong supply chain management (SCM). Three dimensions underlie supplier management: (1) optimal supplier selection, (2) innovative supplier development strategies and (3) meaningful supplier performance assessment mechanisms. 
Traditionally, selection of suppliers is often based on the criterion of price. The cheapest supplier is usually selected without taking into consideration the additional costs this supplier may introduce in the value chain of the purchasing organisation. Thus, the costs related to unreliable delivery, limited quality of goods supplied and poor communication are not involved in the selection process. However, many studies conducted in the area of identification of criteria conclude that supplier selection is based on different interactive criteria, and multi-criteria decision-making techniques become commonplace in supplier selection methodology. This made the methodology complex and technical and also opened new horizons for researchers. The analysis of criteria for selection and measuring the performance of suppliers has been the focus of many academicians and purchasing practitioners since the 1960s. From the purchasing literature, it is fairly easy to abstract a list of at least 50 distinct factors (characteristics of vendor performance) that are presented by various authors as being meaningful to consider in a vendor selection decision (Dickson, 1966: 5-17).

During recent years, the SCM and the supplier/vendor selection process have received significant attention in the business management literature (Verma and Pullman, 1998: 739750). The SCM can be defined as a set of approaches being used efficiently to integrate suppliers, manufacturers, warehouses and stores so that merchandise can be produced and distributed at the right quantities to the right locations and at the right time in order to minimise system-wide costs while satisfying service level requirements. Probably due to the vigorous competition in today's global market, the introduction of products with short life cycles and the heightened expectations of customers have forced business enterprises to invest in and focus attention on their supply chains. In addition, the development of technology plays an important role in motivating the evolution of the supply chain and of the techniques to manage it. In general, a supply chain consists of suppliers, manufacturing centres, warehouses, distribution centres and retail outlets as well as raw materials, workin-progress inventory and finished products that flow between the facilities. Individual businesses no longer compete as autonomous entities but rather by joining a supply chain alliance due to the highly competitive business situation. Therefore, suppliers, manufacturers, logistics companies, and retailers in the supply chain always form stronger alliances, vertically or horizontally, to compete against other supply chains (Lin and Chen, 2004: 159-179). A supply chain is "an integrated process wherein a number of various business entities (i.e., suppliers, manufacturers, distributors, and retailers) work together in an effort to: (1) acquire raw materials/components, (2) convert these raw materials/components into specialised final products, and (3) deliver these final products to retailers" (Beamon, 1998: 281-294).

In most industries the cost of raw materials and component parts constitutes the main cost of a product; in some cases it can account for up to $70 \%$ of the cost (Ghobadian, Stainer, and Kiss, 1993: 321-328). In high-technology companies, purchased materials and services represent up to $80 \%$ of the total product cost (Weber, Current and Benton, 1991: 2-18). 
The raw material purchased for most US firms constitutes $40-60 \%$ of the unit cost of a product. For large automotive manufacturers, the cost of components and parts purchased from outside vendors may total more than $50 \%$ of sales. Purchased material and services represent up to $80 \%$ of total product costs for high technology firms (Burton, 1988: 38-41). Coal purchases for large electric utilities, such as TVA, approach $\$ 1$ billion annually (Bender, Brown, Isaac \& Shapiro, 1985: 106-115). Thus, an insignificant savings in cost of materials purchased from the right supplier may bring a considerable competitive edge in the market place by ensuring maximum value of money expended by the consumers.

The current research aims at selecting the right vendor from a list of vendors within a corporate set-up which is an addition to the current literature. The researcher is privileged to have the scope of using the internal database of a multinational corporation (MNC) to apply the methodology. The name of the MNC has intentionally been kept hidden and a hypothetical name, Company $X$, has been used for reference. Company $X$ is a subsidiary of a UK company operating in Bangladesh and holds $43 \%$ of market share of thread industry. It is a recommended thread manufacturer and market leader in supplying of industrial sewing thread. It imports the basic raw materials like yarn, dyes and chemicals, plastic cones, spare parts and machineries for the purpose of producing thread. The company maintains a list of both local and foreign suppliers and the study is based on the record of 38 suppliers from their database due to the availability of sufficient information. Thus, upfront selection of the supplier is not the ultimate target here. Rather, how a company selects a vendor from the list of vendors is addressed here. The methodology can also be used to remove vendor(s) from the list if they fail to fulfil the sought-after requirements. Sixteen variables have been selected from the available literature and with consultation with the management of Company $X$. The selected variables are grouped using factor analysis. Then, a method known as the Analytic Hierarchy Process (AHP) is used to set weights against each variable through pair-wise comparisons. The calculated weights are used to develop three indices and a relationship is tested through multiple regression analysis. The output of regression can be used for selecting the right vendor. Sufficient motivation behind the formulation of the index is given. It may be irrational to expect improvements in each independent variable. When some variables are grouped into one forming an index, an improvement in index is quite rational and expected. In that case, vendors will be relaxed and the decision will not be aggressive. Vendors will enjoy full independence to set off the potential limitation in one variable against another with a good index value.

\section{METHODOLOGY}

The research methodology applied here starts with the selection of variables and ends with a regression model for vendor selection. Taking the literature review and market survey into account results in 16 variables. These variables are then grouped into three criteria through factor analysis. Such grouping is expected to reduce the response bias due to the 
artificial data reduction technique. AHP is then used to calculate weights through pair-wise comparisons. One may go for similar weights across the variables. Then, the methodology may be biased and it is very apparent that some variables are more important than others. Thus, more important variables should have more weight than less important variables that are done through AHP. The weights thus calculated are then used to form three different indices that are finally regressed to produce a regression model. A schematic presentation, with all the step-by-step procedures, is shown in Figure 1.

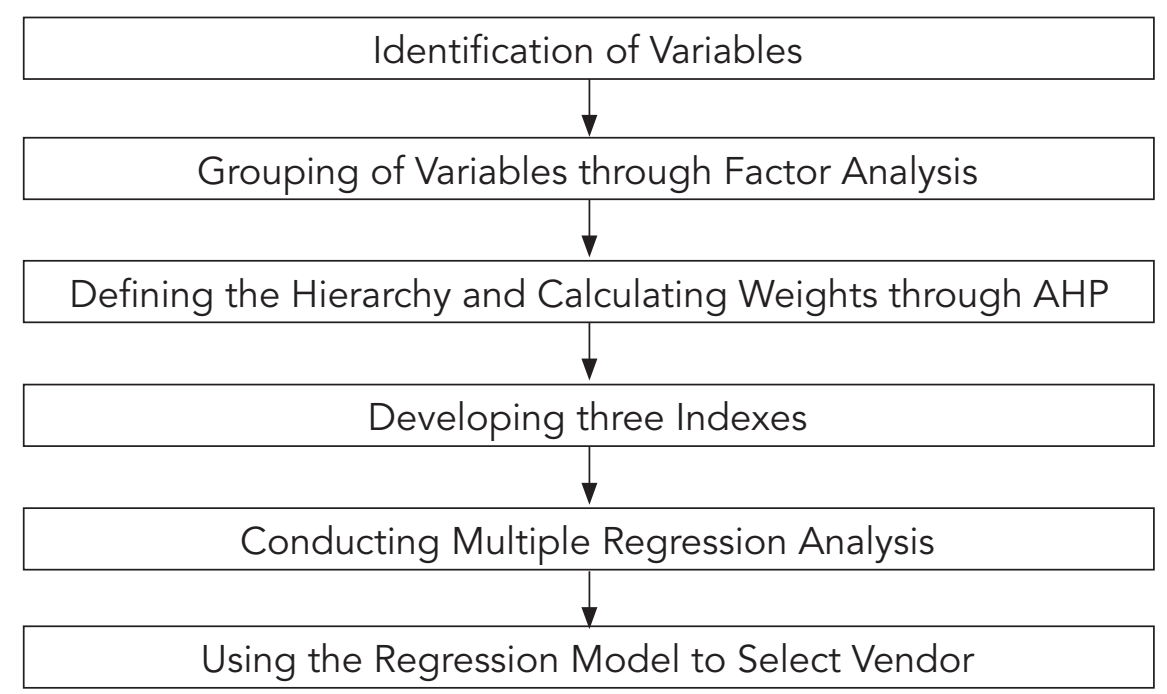

Figure 1: Schematic presentation of research methodology

\section{Variables used}

Studies on variables in vendor selection are enormous. For example, Dickson conducted a study through a questionnaire sent to 273 purchasing agents and managers selected from the membership list of the National Association of Purchasing Managers which resulted in 23 variables (Dickson, 1966: 5-17). The current research is based on a total of 16 variables (Table II). Some of the important variables are discussed in some detail below:

1. Product knowledge: Product knowledge is an important factor for better performance. About $32 \%$ of the vendors considered in the study have satisfactory product knowledge.

2. Being proactive in handling issues: The buyer wants suppliers to address issues as quickly as possible, failing which the buyer will lose trust and confidence in the supplier's level of commitment. Around $30 \%$ of the respondents in the study agreed that suppliers should be speedy enough to handle any queries the buyer may have.

3. Completion timeliness: The time required for shipping the goods to the buyer upon receiving the order (lead time) is an important yardstick to evaluate vendor performance. The lower the lead time is, the better the performance.

4. Satisfaction in dealing with vendors' staff: The interpersonal qualities and professional skills of the vendors' staff play an important role at the time of vendor selection. Some 
studies have considered this behavioural criterion from different perspectives (Buffa and Jackson, 1983: 27-34; Monczka, Giunipero and Reck, 1981: 21-29; and Soukup, 1987: 7-12).

5. Access to vendor: In times of emergency, the buyer needs easy and sometimes informal access to the vendor to reduce the lead time. Many factors again affect this easy access and researchers considered similar geographical location (Ansari and Modarress, 1986: 11-15; Burton, 1988: 38-41; Dickson, 1966: 5-17), service (Bernard, 1989: 1-7); communication system (Dickson, 1966: 5-17); desire for business (Soukup, 1987: 7-12), etc.

6. The vendor's ability to resolve problems: Very often problems occur regarding product specifications, delivery date, payment terms, etc. The vendor's ability to solve such problems is considered to be an important criterion of vendor performance. Many researchers put significant importance on this issue and consider different criteria like technical capability (Hahn, Kim \& Kim, 1986: 2-7; Soukup, 1987); labour relations record (Dickson, 1966; Monczka et al., 1981); training aids (Dickson, 1966); operational controls (Burton, 1988); and production facilities and capacity (Bragg and Hahn, 1989: 41-46; Browning, Zabriskie and Huellmantel, 1983: 19-24) in their studies.

7. Quality of the vendor's product and services: This criterion requires no further clarification and justification. Almost every researcher (almost 98\%) considers this criterion to be an important measure for evaluating vendor performance. Buyers are always quality conscious due to the huge pressure from the ultimate consumers.

8. Pricing: Like quality, pricing is also a common criterion considered in most of the study (Ansari \& Modarress, 1986; Bender et al., 1985; Bernard, 1989; Buffa \& Jackson, 1983; Cardozo \& Cagley, 1971; Dickson, 1966). The vendor who charges the least ultimately gets the order. This is due to the drive of minimising the cost of production.

9. Overall satisfaction with the vendor: Considering all perceived criteria, the overall satisfaction level of the buyer with reference to each vendor under the study was analysed. This criterion is used to test the response bias of the respondents. The ultimate result concludes that the respondents were not biased at the time of responding to each question.

10. Overall satisfaction of the vendor with the buyer: In this study, the researcher had the privilege of including the vendors' perspective in the ultimate selection process. Vendor performance in serving a buyer also depends on the level of satisfaction on the part of the vendor with reference to the buyer in question in terms of billing, payment procedure, behaviour, time elapse before receiving payment, and terms and conditions, etc.

11. Experience of the vendor: Vendor experience in terms of years in the business, number of orders handled, number of problems resolved, and annual turnover are also important issues that set the performance level. The researcher considered all of these factors related to experience of the vendor. 


\section{Types of vendor}

This survey was conducted on two categories of vendor: local and foreign. Local vendors are from locally registered Bangladeshi companies and foreign vendors are those registered in a foreign country but who operate in Bangladesh through their local branch offices. The distribution of vendors is shown in Table I.

Table I: Distribution of local and foreign vendors

\begin{tabular}{|c|l|l|l|l|}
\hline & Frequency & Per cent & Valid per cent & Cumulative per cent \\
\hline Valid Local & 28 & 73.7 & 73.7 & 73.7 \\
Foreign & 10 & 26.3 & 26.3 & 100.0 \\
Total & 38 & 100.0 & 100.0 & \\
\hline
\end{tabular}

The above result shows that most of the respondents included in the survey were local vendors as they were easy to get in touch with. However, a number of foreign vendors around $26 \%$ - were also included in the survey. Information with respect to the 16 variables was collected from all of the 38 vendors considered in the study and then grouped, indexed and regressed to reach to a conclusion.

\section{ANALYSIS AND FINDINGS}

\section{Factor analysis}

Factor analysis is a statistical method used to describe variability among observed variables in terms of fewer unobserved variables called factors. It is applied as a data reduction or structure detection method. It is a multivariate technique and was employed in the study for the purpose of analysing the data. The Principal Component Method is considered appropriate as the primary purpose is to determine the minimum number of factors that would account for the maximum variance in the data collected. The data was analysed by using SPSS, version 11. The result is that three factors were extracted from the data collected. Only factors with eigenvalue(s) greater than 1 were retained. By comparing the Varimax Rotated Factor Matrix with the Unrotated Factor Matrix (called the component matrix), rotation provided simplicity and has enhanced interpretability. From the rotated factor matrix, three factors have been extracted from 16 variables as shown in Table II. 
Table II: Extracting factors

\begin{tabular}{|l|l|}
\hline Factors & Criteria \\
\hline $\begin{array}{l}\text { Factor 1: } \\
\text { Performance }\end{array}$ & $\begin{array}{l}\text { Timeliness of delivery, quality of product upon delivery, overall quality } \\
\text { of product, efficiency in handling problems, quality of service provided, } \\
\text { competitiveness of terms and conditions, expertise of staff }\end{array}$ \\
\hline $\begin{array}{l}\text { Factor 2: } \\
\text { Satisfaction }\end{array}$ & $\begin{array}{l}\text { Timeliness of getting billing certificate after completion of work, timeliness of } \\
\text { payment after invoicing, satisfaction with payment procedure, satisfaction with } \\
\text { terms and condition, satisfaction with co-operation of buyer's staff }\end{array}$ \\
\hline $\begin{array}{l}\text { Factor 3: } \\
\text { Experience }\end{array}$ & $\begin{array}{l}\text { Number of purchase orders successfully completed, value of purchase orders, } \\
\text { business with buyer in months, years of operation }\end{array}$ \\
\hline
\end{tabular}

The factor analysis revealed that the 16 variables that were initially selected were categorised into three factors, namely, performance, satisfaction and experience. Communalities show how much of the variance in the variables has been accounted for by the extracted factors. By analysing communalities, it was found that the factor loading for 'years of operation' was comparatively low, i.e. $48.9 \%$ of the total variance. However, the remaining 15 variables were explained reasonably well as evidenced by the high factor loadings of above 0.6 (more than 60\%). The variables like 'expertise of staff' and 'years of operation' have factor loadings of $81 \%$ and $87.1 \%$ respectively.

As mentioned already, three factors have been extracted from the extraction statistics by using the cut-off initial eigenvalue of 1.00. The factor loading patterns and percentage of variance for each of the factors were derived by using orthogonal varimax rotation. The first factor accounted for $20.343 \%$ of the variance explained as compared to $15.6 \%$ in the rotated matrix. The factor solution was derived from the component analysis with orthogonal varimax rotation of the 16 variables listed for the purpose of the study. The idea of rotation is to reduce the number of factors in which the variables under investigation have high loadings. Rotation does not actually change anything but makes the interpretation of the analysis easier. Factor 1 is entitled 'performance' comprising seven variables, factor 2 is entitled 'satisfaction' comprising five variables, and factor 3 includes a total of four variables under the heading 'experience'. These factors can be used as variables for further analysis. The extracted factors not only reveal the important dimensions associated with the selection of vendors but also reveal the important categorisation of the variables.

\section{Analytical hierarchy process (AHP)}

The analytic hierarchy process (AHP) is one of the most popular decision-making methods that deals with multiple criteria. Each criterion and sub-criterion is weighted through quantification of human judgments in a scientific manner. The option of testing bias in 
human judgment is also there. If the judgment is not consistent, the methodology offers adjustments to the judgment until it becomes consistent.

Current research has already identified some criteria and sub-criteria from which to choose the right vendor from a set of vendors. These criteria and sub-criteria have a strong impact on profitability through the selection of the optimal vendor. But the degree of all of these criteria and sub-criteria may differ significantly. Thus, it is felt that AHP should be used to choose the relative weight of each criterion and sub-criterion. The AHP methodology as applied here passes three sequential steps, as follows:

1. Designing hierarchy of criteria and sub-criteria

2. Conducting a pair-wise comparison

3. Consistency check in validating pair-wise comparisons.

\section{Design of hierarchy}

The hierarchy of variables has already been identified in the factor analysis phase. AHP (You \& Hongli, 2007: 6250-6253) formulates the decision problem as a structure of hierarchy. The problem is placed at the top of the hierarchy while the middle layer contains all the criteria and sub-criteria needed in the selection process. The alternatives are placed at the lowest layer of the hierarchy. Hierarchy of criteria as selected in factor analysis is shown in Figure 2 and will be used for AHP.

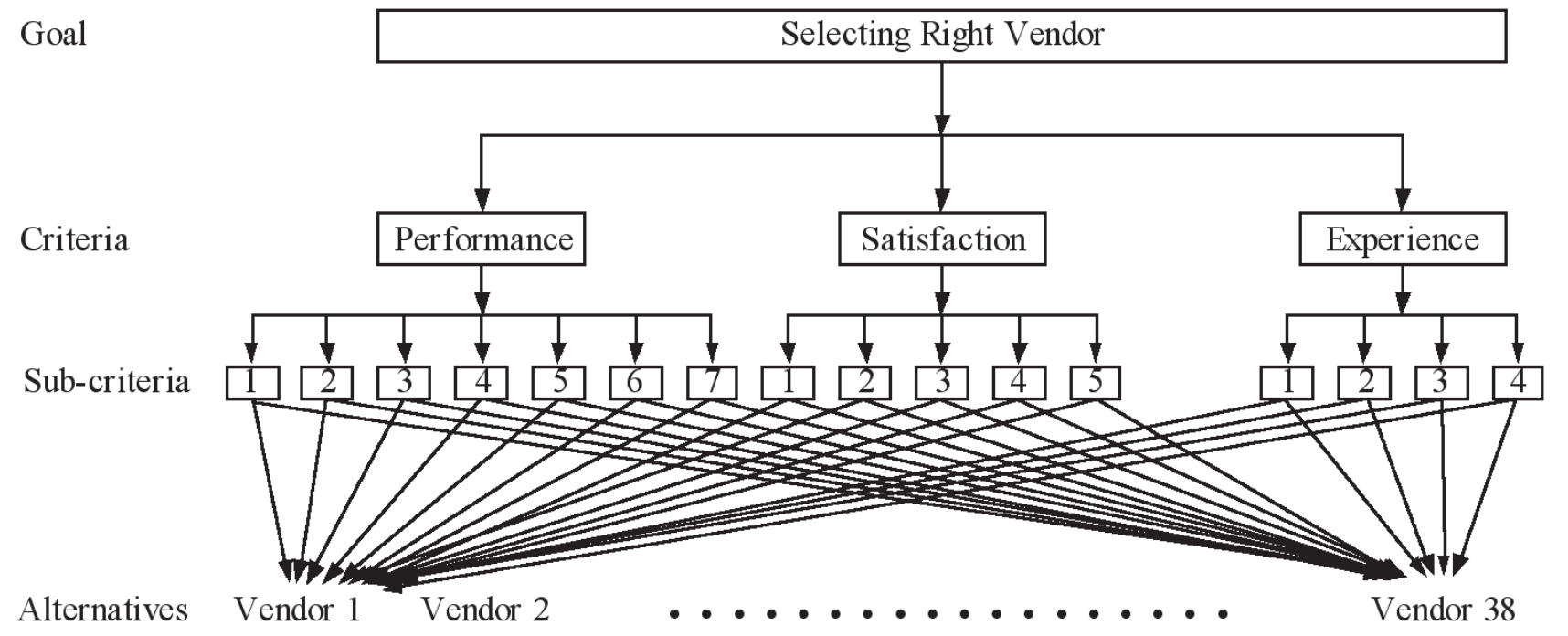

Figure 2: Hierarchy of criteria

Factor analysis grouped all of the 16 known variables into three unknown variables termed as performance, satisfaction and experience. In AHP, these are considered as criteria. Criterion 'performance' has seven sub-criteria, 'satisfaction' has five and 'experience' has four. All of these criteria and sub-criteria are used to choose the right vendor from a list of 38 . 


\section{Pair-wise comparisons}

After completion of the hierarchy, a prioritisation procedure is followed to assign the priority to the elements of the hierarchical structure. Prioritisation is a type of judgment that identifies the dominance of one element over another. This kind of judgmental procedure is constructed by using pair-wise comparison (Bayazit \& Karpak, 2005) among the elements. AHP uses a standardised comparison scale of nine levels to make the pair-wise comparison such as equally important, moderately important, strongly important, very strongly important, extremely important, etc. All of these are the reflection of human judgment in verbal form showing different degrees of preference that need quantification. All possible form of human judgment is quantified with numeric values assigned as shown in Table III under AHP.

Table III: Scale for relative importance

\begin{tabular}{|c|l|c|l|}
\hline $\begin{array}{c}\text { Intensity of } \\
\text { importance }\end{array}$ & Definition & $\begin{array}{c}\text { Intensity of } \\
\text { importance }\end{array}$ & Definition \\
\hline 1 & Equal importance & 2 & Weak \\
\hline 3 & Moderate importance & 4 & Moderate plus \\
\hline 5 & Strong importance & 6 & Strong plus \\
\hline 7 & Very strong importance & 8 & Very, very strong \\
\hline 9 & Extreme importance & & \\
\hline
\end{tabular}

To exemplify the process of pair-wise comparison, let us consider our three criteria: performance (P), satisfaction (S) and experience (E). The pair-wise comparison starts each time with the question: "Which criterion is better than the other and by how much in comparison with the other?" Let us make a relative scale to measure the priority of one criterion over another. There is no requirement that the scaling necessarily falls between 1 and 9 but for qualitative data such as preference, ranking and subjective opinions, it is suggested (Saaty, 1988) to use the scale of 1 to 9 with the meaning as presented in Figure 3.

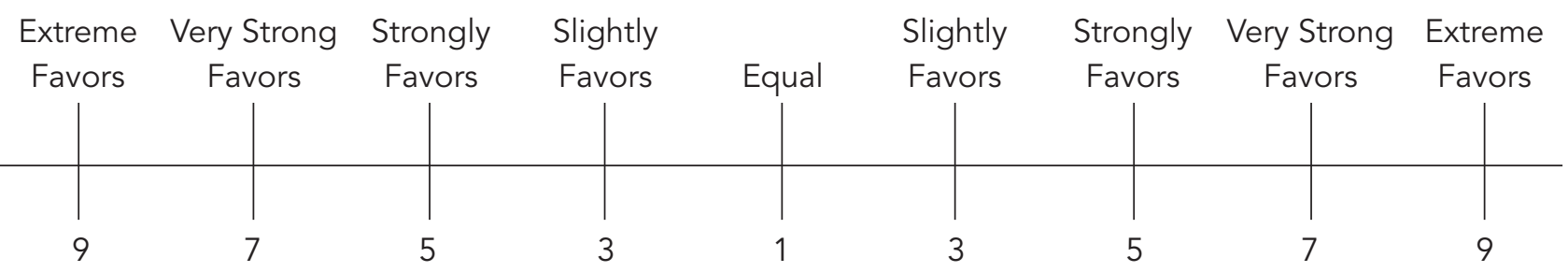

Figure 3: Priority scale 
If $\mathrm{P}$ is better than $\mathrm{S}$, then a number is marked between 1 and 9 on the left-hand side, while it is marked on the right-hand side if $\mathrm{S}$ is better than $\mathrm{P}$, as shown in Figure 4.

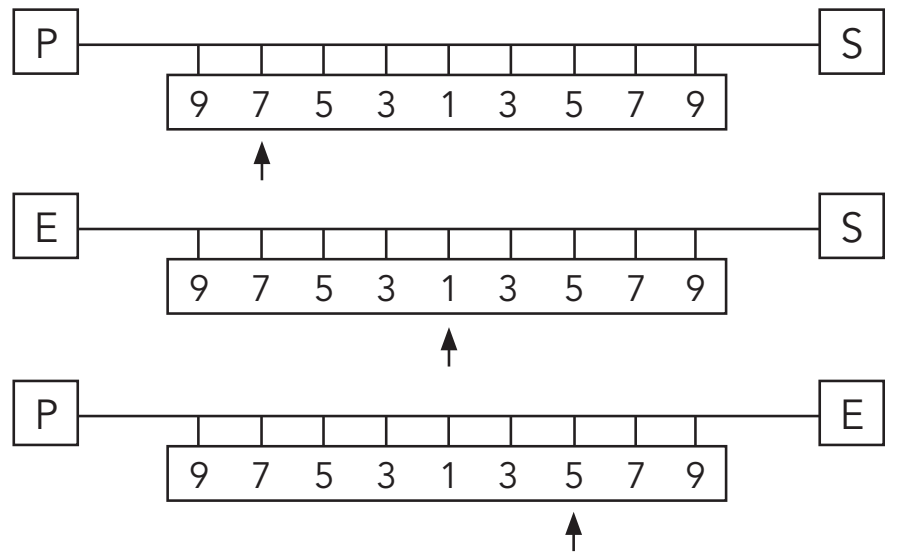

Figure 4: Pair-wise comparison of three criteria

Here $\mathrm{P}$ is preferable to $\mathrm{S}$ by a factor of 7 and hence $\mathrm{S}$ is preferable to $\mathrm{P}$ by a factor of $1 / 7$ as it is the reciprocal value of factor 7 . Similarly, this can be done for all other criteria.

The number of comparisons is totally dependent on the number of variables to be compared. Three criteria ( $\mathrm{P}, \mathrm{S}$ and $\mathrm{E}$ ) require a maximum of three pair-wise comparisons as shown in Figure 4. The maximum possible number of combinations in pairs may be computed by using the equation as shown in Table IV below:

Table IV: Number of comparisons

\begin{tabular}{|l|l|l|l|l|l|l|l|c|}
\hline Number of criteria & 1 & 2 & 3 & 4 & 5 & 6 & 7 & $\mathrm{n}$ \\
\hline Number of comparisons & 0 & 1 & 3 & 6 & 10 & 15 & 21 & $\frac{n(n-1)}{2}$ \\
\hline
\end{tabular}

Let $C=\left\{C_{j} \mid j=1,2, \ldots, n\right\}$ be the set of criteria. Firstly decision-makers need to make the pair-wise comparisons among the criteria to express the dominance of one criterion over another. For $n$ number of criteria $\frac{n(n-1)}{2}$ pair-wise comparisons are needed. The result can be preserved in an $(n \times n)$ evaluation matrix $A$ where each element $a_{i j}$ represents a pair-wise comparison between $C_{i}$ and $C_{j}$ with $\{i=1,2,3, \ldots, n\}$ and $\{j=1,2,3, \ldots, n\}$. $a_{i j}$ taking values from 1 to 9 as shown in Table III. 


\section{Consistency check}

AHP uses human judgment and hence inconsistency may arise in the pair-wise comparison. So, the consistency of the pair-wise comparison must be calculated through a consistency index $(C I)$. The $\mathrm{CI}$ is expressed as:

$$
\mathrm{CI}=\frac{\lambda_{\max }-\mathrm{n}}{\mathrm{n}-1}
$$

The final consistency ratio (CR) (Bhutta \& Huq, 2002: 126-135) is calculated as the ratio of the $C I$ and the random consistency index $(R C I)$ and is calculated as $\mathrm{CR}=(\mathrm{CI} / \mathrm{RCI})$. RCI is the index value selected from Table $V$ with respect to the different rank of matrix. If the value of $C R$ is smaller or equal to $10 \%$, the inconsistency is acceptable while for the value of $C R$ greater than $10 \%$, it needs to revise the subjective judgment.

Table V: Random consistency index (RCI)

\begin{tabular}{|l|l|l|l|l|l|l|l|l|}
\hline Matrix rank & 1 & 2 & 3 & 4 & 5 & 6 & 7 & 8 \\
\hline$R C I$ & 0 & 0 & 0.58 & 0.90 & 1.12 & 1.24 & 1.32 & 1.41 \\
\hline
\end{tabular}

The major difficulty in the above-mentioned AHP methodology is that when a large number of alternatives are competing, AHP becomes inefficient and a huge computational complexity arises. However, software may be used to avoid the computational complexity. For example, Expert Choice $\bigcirc$ software is used here to calculate the respective weights of all criteria and sub-criteria used in this study with the following results as shown in Figure 5. In every case, the $C R$ results are less than $10 \%$ meaning that the judgment was consistent.

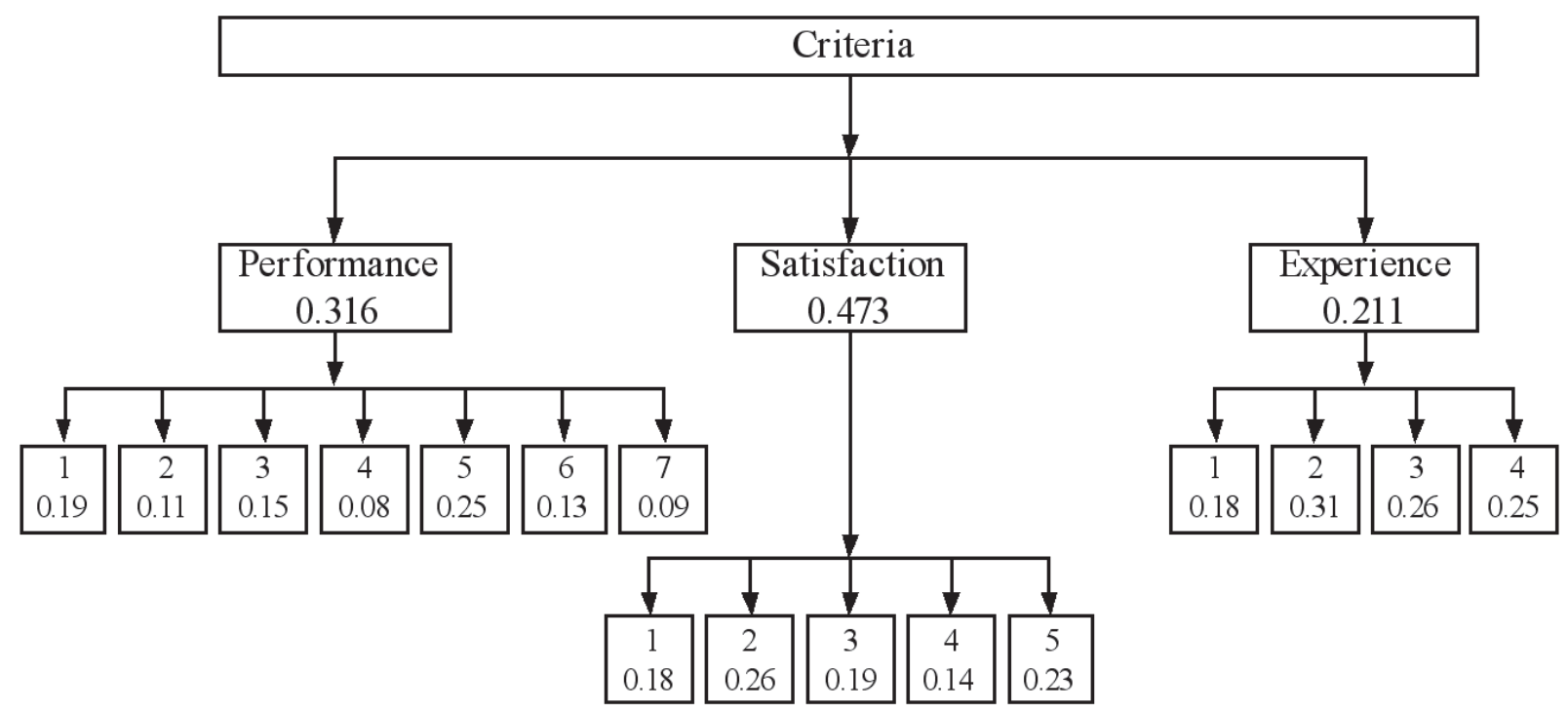

Figure 5: Weights of criteria and sub-criteria 


\section{Multiple regression analysis}

The weights, as calculated under AHP, have been used to develop three indices entitled Vendor Performance Index (VPI), Vendor Satisfaction Index (VSI), and Vendor Experience Index (VEI). VPI includes seven variables, VSI includes five variables and VEI includes the remaining four variables. These variables and their respective weights are used to calculate index value and then these values are regressed for all 38 vendors. Thus, a multiple regression analysis with one dependent and two independent variables is conducted. The list of variables with their operational definitions is given in Table VI.

Table VI: Variables used in multiple regression analysis

\begin{tabular}{|c|c|c|}
\hline Variables & Notations & Operational definitions \\
\hline \multicolumn{3}{|l|}{ A. Dependent variable } \\
\hline Vendor Performance Index & $V P I$ & $\begin{array}{l}\text { VPI includes seven dimensions that are } \\
\text { most relevant to vendor performance } \\
\text { as identified earlier }\end{array}$ \\
\hline \multicolumn{3}{|l|}{ B. Independent variables } \\
\hline Vendor Experience Index & $V E I$ & $\begin{array}{l}\text { VEI is measured by using four criteria } \\
\text { that strongly indicate vendor's level of } \\
\text { experience }\end{array}$ \\
\hline Vendor Satisfaction Index & $V S I$ & $\begin{array}{l}\text { VSI is measured by five issues relevant } \\
\text { to vendor's satisfaction with buyer }\end{array}$ \\
\hline
\end{tabular}

Considering the above variables with the definitions and notations, the regression model is presented below:

$\mathrm{VPI}=\beta_{0}+\beta_{1} \mathrm{VEI}+\beta_{2} \mathrm{VSI}+\varepsilon$

Here, $\beta_{0}$ is the intercept of the regression line; $\beta_{1}$ and $\beta_{2}$ are the coefficients of the respective independent variables; and $\varepsilon$ represents the random error with the mean zero.

\section{Assumptions of the model}

The model is based on some assumptions. It is assumed that other variables that have an influence on vendor performance such as the economic condition, political situation, labour productivity, etc. is constant. To use the ordinary least square method, further assumptions were made regarding some standard clauses which are known as the classical group of assumptions. These are:

1. $X_{i}^{\prime}$ s fixed or $X_{i}^{\prime}$ s independent of $\varepsilon_{i}^{\prime} \mathrm{s}$.

$[i=1,2, \ldots \ldots \ldots \ldots, n]$

2. $\varepsilon_{i}^{\prime}$ s random variables with mean $=0$.

$[i=1,2, \ldots \ldots \ldots \ldots, n]$

3. $V\left(\varepsilon_{i}\right)=E\left[\varepsilon_{i}-E\left(\varepsilon_{i}\right)\right]^{2}=E\left(\varepsilon_{i}{ }^{2}\right)=\sigma^{2} E$ is constant.

$[i=1,2, \ldots \ldots \ldots \ldots, n]$

4. $E_{i}^{\prime}$ 's are independent of each other.

$[i=1,2$,

5. There is no set of non-zero constants.

$[i=1,2$, $n]$ 
$C_{0}, C_{1}, \cdots \cdots \cdots, C_{k}$ such that,

$C_{0}+C_{1} X_{1}+\ldots \ldots \ldots \ldots+C_{k} X_{k}=0$. So,

$X_{1}, \cdots \ldots \ldots . . ., X_{k}$ are linearly independent.

\section{Regression model}

The data regarding all of the 38 vendors have been manipulated and analysed using the SPSS program which results the following regression equation:

$\mathrm{VPI}=-1.45+0.371 \mathrm{VEI}+0.702 \mathrm{VSI}+\varepsilon$

As per the model, the intercept of the line $\left(\beta_{0}\right)$ becomes -1.45 which means if all the independent variables takes the value zero, the VPI will be -1.45. If the VEI increases by 1 , on average, the VPI will increase by an additional $0.371\left(\beta_{2}\right)$ and if the VSI increases by 1 , on average, the VPI will increase by an additional $0.702\left(\beta_{3}\right)$. Multicollinearity does not seem to represent a threat to the results. The values of Variance Inflation Factor (VIF) are well below the critical value of 10 and the tolerance value is close to 1 , indicating a high independence among the variables.

\section{FINDINGS}

The important findings of the study are that both the VEI and the VSI are significant in explaining the performance level of vendors. Therefore, the findings indicate that the vendor's performance is positively related to vendor's experience and satisfaction. It is imperative for the supply chain managers of the company to include the supplier's experience and satisfaction as important factors for their model. When the problem of supplier selection arises, it should be based on performance. And as per the model, performance becomes a function of experience and satisfaction. Thus, every prospective candidate should come through the full process before final selection. It requires the completion of the two indices viz., VEI and VSI. Later on, the value should be put on the model and the model ends up with a value indicating the performance level. The greater the value of performance is, the greater is the possibility of the selection. The company may also run the general regression at regular intervals to test whether there is any change in variables and their interrelationships in order to adjust the model for the same.

\section{CONCLUSION}

The problem of supplier selection essentially deals with the selection of the right supplier and their quota allocation (Kaur, Verma \& Mahanti 2008: 1-8) which also requires that a variety of vendor attributes such as price and quality needs to be considered (Junyan, Ruiqing \& Wansheng, 2008: 106-111). It thus becomes a common issue in the multi-criteria decision-making process of every company. With the development of 23 criteria by Dickson 
in the 60s, further research extended the list to a greater extent. Criteria on which vendor selection is based rest ultimately on the company and the product under consideration. This paper, for example, deals with the identification of the right supplier from a dedicated list of suppliers on the basis of suppliers' experience and satisfaction with the buyers. And it has been statistically proven that suppliers' performance is explained by experience and satisfaction.

There is sufficient scope for researchers to identify sub-criteria of experience and satisfaction; for example, the paper proposes four sub-criteria for experience and other five sub-criteria for satisfaction. These are ultimately considered as criteria for defining the level of performance of suppliers in the form of different indices and the interrelationship thereof. Whatever the criteria selected or methodology used, the paper considers the suppliers' perspective at the time of selecting them. It has been proved that the performance level of suppliers also depends on the extent of their satisfaction with the buyers. The same supplier may have different performance levels for different buyers due to change in satisfaction with the buyers. Thus, it is also imperative that buyers, in order to enjoy maximum performance from the suppliers, try to keep them highly satisfied. It is more important to have a fully committed and dedicated supplier base, compared to that of competitors, than to make negligible savings, say in terms of cost of material. This is the finding that has come out of the research; the personnel responsible for the selecting suppliers would benefit from incorporating this issue into their current vendor selection methodology. Factor analysis helps to reduce the burden of dealing with numerous variables, and AHP helps to set the priority through respective weights to form the indices in a normalised way; and finally, the multiple regression set the decision rule of choosing the right vendor. Here, AHP may also give the final selection of vendors if the relative weights of three criteria are used. However, the application of multiple regression helps to show the important relationships among the criteria that are also important for rationalising the choice of those criteria for final selection. 


\section{REFERENCES}

Ansari, A. and Modarress, B. 1986. Just-in-time purchasing: Problems and solutions. Journal of Purchasing and Materials Management, 22(3): 11-15.

Bayazit, O. and Karpak, B. 2005. An AHP application in vendor selection, ISAHP'05.

Beamon, B.M. 1958. Supply chain design and analysis: Models and methods. International Journal of Production Economics, 55(3), 1998: 281-294.

Bender, P.S., Brown, R.W., Isaac, M.H. and Shapiro, J.F. 1985. Improving purchasing productivity at IBM with a normative decision support system. Interfaces, 15(3): 106-115.

Bernard, P. 1989. Managing vendor performance. Production and Inventory Management Journal, 30(1): 1-7.

Bhutta, K.S. and Huq, F. 2002. Supplier selection problem: a comparison of the total cost of ownership and analytic hierarchy process approaches. Supply Chain Management: An International Journal, 7(3): 126-135.

Bragg, D.J. and Hahn, C.K. 1989. Material requirements planning and purchasing. Journal of Purchasing and Materials Management, 25(1): 41-46.

Browning, J.M., Zabriskie, N.B. and Huellmantel, A.B. 1983. Strategic purchasing planning. Journal of Purchasing and Materials Management, 19(1): 19-24.

Buffa, F.P. and Jackson, W.M. 1983. A goal programming model for purchase planning. Journal of Purchasing and Material Management, 19(3): 27-34.

Burton, T.T. 1988. JIT/repetitive sourcing strategies: Tying the knot with your suppliers. Production and Inventory Management Journal, 29(4): 38-41.

Cardozo, R.N. and Cagley, J.W. 1971. Experimental study of industrial buyer behavior. Journal of Marketing Research, (8): 329-934.

Dickson, G.W. 1966. An analysis of vendor selection: Systems and decisions. Journal of Purchasing, 1(2): 5-17.

Ghobadian, A., Stainer, A. and Kiss, T. 1993. A computerized vendor rating system, Proceedings of the First International Symposium on Logistics, The University of Nottingham, Nottingham, UK: 321-328. 
Hahn, C.K., Kim, K.H. and Kim, J.S. 1986. Costs of competition: Implications for purchasing strategy. Journal of Purchasing and Materials Management, 22(3): 2-7.

Junyan, W., Ruiqing, Z. and Wansheng, T. 2008. Fuzzy programming models for vendor selection problem in a supply chain. Tsinghua Science and Technology, 13(1): 106-111.

Kaur, P., Verma, R. and Mahanti, N.C. 2008. Vendor selection problem using fuzzy analytical hierarchy process. International Journal of Soft Computing, 3(1): 1-8.

Lin, C.-W. R. and Chen, H.-Y.S. 2004. A fuzzy strategic alliance selection framework for supply chain partnering under limited evaluation resources. Computers in Industry, 55(2): 159-179.

Monczka, R.M., Giunipero, L.C. and Reck, R.F. 1981. Perceived importance of supplier information. Journal of Purchasing and Materials Management, 17: 21-29.

Porter, M.E. 1980. Competitive strategy; techniques for analyzing industries and competitors, New York, Free Press, 397.

Saaty, T.L. 1988. The Analytic Hierarchy Process, New York: McGraw-Hill.

Soukup, W.R. 1987. Supplier selection strategies. Journal of Purchasing and Materials Management, 26(1): 7-12.

Verma, R. and Pullman, M.E. 1998. An analysis of the supplier selection process. Omega, 26(6): 739-750.

Weber, C.A., Current, J.R. and Benton, W.C. 1991. Vendor selection criteria and methods. European Journal of Operational Research, (50): 2-18.

You, F. and Hongli, L.I.U. 2007. Information system outsourcing vendor selection based on AHP. International Conference on Wireless Communications, Networking and Mobile Computing, pp. 6250-6253. 